\title{
PAPER
}

\section{Coping with ecological catastrophe: crossing major thresholds}

\author{
John Cairns, Jr.* \\ Department of Biology, Virginia Polytechnic Institute and State University, Blacksburg, Virginia 24061, USA
}

\begin{abstract}
The combination of human population growth and resource depletion makes catastrophes highly probable. No long-term solutions to the problems of humankind will be discovered unless sustainable use of the planet is achieved. The essential first step toward this goal is avoiding or coping with global catastrophes that result from crossing major ecological thresholds. Decreasing the number of global catastrophes will reduce the risks associated with destabilizing ecological systems, which could, in turn, destabilize societal systems. Many catastrophes will be local, regional, or national, but even these upheavals will have global consequences. Catastrophes will be the result of unsustainable practices and the misuse of technology. However, avoiding ecological catastrophes will depend on the development of eco-ethics, which is subject to progressive maturation, comments, and criticism. Some illustrative catastrophes have been selected to display some preliminary issues of eco-ethics.
\end{abstract}

KEY WORDS: Ecological thresholds - Ecological catastrophes - Climate change • Eco-ethics · Overpopulation $\cdot$ Sustainability $\cdot$ Ecological deficits $\cdot$ Oceanic fisheries

Resale or republication not permitted without written consent of the publisher

If we could first know where we are, and whither we are tending, we could then better judge what to do, and how to do it.

Abraham Lincoln

We must prevent human tragedy rather than run around trying to save ourselves after an event has occurred. Unfortunately, history clearly shows that we arrive at catastrophe by failing to act when we should have acted. The opportunity passes us by and the next disaster is always more difficult and compounded than the last one.

Eleanor Roosevelt

\section{ISSUE STATEMENT}

Hardin, Ehrlich, Meadows, Brown, and others have covered many of the topics in this manuscript. One new development is public attention to sustainability. Despite some semantic differences, sustainable use of planet, sustainable development, and sustainability all have the primary goal of leaving a habitable planet for posterity, which includes not damaging the biospheric life support system. Another new factor is increasing recognition of the rapid massive changes in the ecological, physical, and social world (e.g. McNeill 2000).
This rate of change and the magnitude of the damage to ecological integrity of the planet are unprecedented in human history. A number of statements made at United Nations Conferences (e.g. Stockholm, Rio, and Johannesburg) recognize these new circumstances. Sustainable use of the planet is a vision that is simultaneously global, regional, and individual. This vision places the individual in a setting that has the potential to exist indefinitely. It differs from the egocentric vision all too common in the twentieth and twenty-first centuries of an individual or a nuclear family surrounded by material possessions. Each individual should have a 
vision beyond material possessions of the kind of world he/she wishes to inhabit and the one envisioned for one's descendants. Material World (Menzel 1994) contains intimate pictures of average families in different cultures surrounded by all their possessions. The disparity of possessions between families is enormous. Also conveyed by both pictures and text is how the family is defined by more than material possessions. Regrettably, it is impossible to depict the ecosystem each family depends upon because it is a larger area than the family inhabits; on the other hand, differences in the size of ecological footprints are easy to visualize. Even in affluent countries, the wishes of individuals for the future are for larger houses or specific material possessions, such as a larger television set, more sophisticated VCR, a different color refrigerator, and more home tools. These wishes are not the holistic vision needed for sustainable use of the planet, which, instead, asks how much material consumption by humankind can Earth's ecological life support system afford? This sustainability-ethics question is of increasing importance as the planet's human population increases and natural resources decrease.

The world is becoming more uniform due to the internet, economic globalization, mass migrations with interbreeding of individuals with different geographic origins, and the like. McNeill and McNeill (2003) describe human society as one huge web of cooperation and competition sustained by massive flows of information and energy (one might add natural resources). Globalization has vastly increased opportunities for invasive species (usually to the detriment of indigenous species) that reduce diversity. Decline of diversity leads to increased vulnerability, as agricultural monoculture has shown. Uniformity increases vulnerability to pests and diseases, which often quickly become resistant to pesticides and antibiotics. These changes increase the likelihood of both societal and ecological instability, which increases the potential for catastrophes to occur.

\section{ECOLOGICAL DEFICITS}

Ecological catastrophes are most likely to occur in areas or nations with existing ecological deficits. In a sense, this situation is comparable to the risk of a nation with a large financial deficit losing financial stability. Ecological deficit is defined here as a situation in which natural capital (e.g. Hawken et al. 1999) has been diminished; ecosystem services are lessened and, arguably most important, natural resources are not used in a sustainable way. In economic terms, natural capital may be regarded as monetary capital and ecosystem services as the interest on that capital.
When natural capital is preserved and accumulated, ecosystem services will continue to be reliable and the more capital, the greater the services. In short, living sustainably diminishes the probability of catastrophes.

The remarkable advance of information systems, science, and technology has given humankind the ability to improve its relationship with the natural systems that constitute the ecological life support system, which maintains the conditions essential to human survival. Regrettably, having the ability to use reason and intelligence (in short, to act wisely) does not mean humankind will do so.

\section{THE WHOLE VERSUS THE PARTS}

As is the case with the human body and mind, health is best maintained with a holistic approach that will facilitate prioritization of those components most needing attention. In short, excessive preoccupation with the parts may result in missing the performance of the whole. Advocates of sustainable use of the planet emphasize the problem (unsustainable practices), the consequences of the problem (catastrophic events for both humankind and natural systems), and the solution to the problem (living sustainably). On a philosophical level, general agreement exists that humankind should leave a habitable planet for its descendants and those of other species. However, on the surface, the components of sustainability are not unique. On the basis of these surface components (e.g. population control, resource allocation, and avoiding such things as global warming), nations, ethnic groups, etc. have bitter arguments, even terrorism and/or war. Individuals and nations profess a commitment to the principles and goals of sustainable development but are often unwilling to change their practices and behaviors to meet the goals and conditions essential to sustainability (e.g. Agyeman et al. 2003).

A somewhat similar situation exists for the world's major religions (e.g. Islam, Judaism, and Christianity) - most favor peace but their disagreements block achieving true peace. In addition, there is crossfire between corporate fundamentalists and those of atavistic religious movements (e.g. Orr 2004), resulting in a polarization of views rather than mutualism. In such instances, differences in achieving and maintaining sustainability must be tolerated and the diversity of cultures honored. Sustainability and religious conflict may appear to be more isolated from each other than they actually are. It is highly probable that religious divisiveness will be used to exacerbate conflicts over sustainability issues. 


\section{ILLUSTRATIVE GLOBAL ECOLOGICAL CATASTOPHES}

The use of natural resources (natural capital and the ecosystem services it provides) beyond their regenerative capacity, if continued, will cause catastrophes. Since the biosphere is an interactive system, cascading effects producing simultaneous catastrophes are probable. The illustrative global ecological catastrophes that follow are intended to persuade humankind to shift to sustainable practices that will reduce the risk of catastrophes.

\section{Resource wars}

Angola suffered a quarter-century of nearly uninterrupted civil war sparked by ideological differences (Swarms 2002). The United Nations' Children's Fund (Renner 2002) has described Angola as 'the worst place in the world to be a child.' The 2001 Human Development Index (United Nations Development Programme 2001), which is a broad gauge of social and economic progress, ranked Angola 161st out of 173 nations. Both the government and rebel forces (UNITA) used Angola's natural resource wealth (diamonds and oil), selling most of these resources for weapons and personal accumulation of wealth. Thus, resource-driven greed proved to be a powerful fuel for continuing the conflict, which left a million people dependent on foreign food aid (Renner 2002).

A significant number of resource wars continue on the planet (Renner 2002). Although Angola is an extreme case, in terms of the estimated revenue from a resource war, it might well portend the future, in that resource wars may be masked by claims of political oppression, denial of minority rights, or religious differences. If these wars were truly fought over ideological differences, large amounts of wealth from resource sales would not end up in the pockets of a few individuals.

In many instances, ethnic and religious conflicts are used as an opportunity to derive revenues by pillaging natural resources. This scenario is difficult to prove since the pillagers may claim to be driven by an unresolved grievance rather than greed. Natural resources are one of the few sources of wealth and the power derived from wealth in poorer societies. Of course, any nation can easily be diverted from protection of natural resources by war, terrorism, economic problems, and civil unrest. Unscrupulous individuals are quick to take advantage of such opportunities and to foster whatever improves or prolongs their access to natural resources. Either resource wealth or resource scarcity can result in resource wars (e.g. Cairns 2003) because wealth must be continually protected and scarcity may cause the 'have nots' to attempt to acquire resources by violence or threats of violence. English philosopher Thomas Hobbes believed that the only way out of this desperate state is to make a social contract and establish the state to keep peace and order. Hobbes subscribed to a very authoritarian version of the social contact. $^{1}$

Renner (2002, his Table 2, p. 15) summarizes 16 cases of the impact of resource wealth on armed conflict. The duration, intensity, and key characteristics varied, as did whether or not the conflict was initiated by resource wealth. Unquestionably, the impact on the resources was unfavorable in all cases. In a number of cases, resource conflicts have led to UN sanctions (Renner 2002, Table 4, p. 55). Regrettably, in some cases, such as diamond smuggling, the activities have been reduced but not eliminated.

\section{Who suffers - who gains?}

If human society or the biosphere is destabilized, enormous suffering will occur in both humans and other species. However, as Hendrickson (2002) notes, two far-reaching political changes in the United States are: (1) a pronounced emphasis on unilateral methods in the conduct of American foreign policy and (2) the new American strategic doctrine of preventative war. As natural resources become scarcer and under increasing pressure, there is at least the possibility of moving toward the world envisioned by Hobbes of anarchy and power politics. These two are the most recent additions to the causes of ecological catastrophes.

\section{The Florida Everglades}

A good example of an ecological catastrophe supported by the US Congress and private enterprise and only weakly resisted by the general public is the exploitation of the Everglades in the southern part of Florida in the US. The original Everglades was not only a huge ecosystem, but it was (and still is) a unique subtropical ecosystem. It is rich in species that are characteristic of the subtropics and contains many 'ecological islands' and unique features, such as cypress domes. The area is also a major stop for migratory birds and a 'nursery ground' for many species of fish.

The Everglades originally began just below the area now occupied by the city of Orlando and extended

${ }^{1}$ See http://oregonstate.edu/instruct/phl302/philosopher/hobbes.html 
south to the lower tip of Florida (Dovell 1947). Ecological damage to the Everglades began in the mid-1850s after Smith $(1848$, p. 68) reported to the US Congress that draining the Everglades by four to five feet would create a 'tropical breadbasket of no trifling advantage to the whole nation.'

Of course, protests began of 'senseless vandalism of the Everglades' (e.g. Simpson 1920, Small 1929), but it took many years for the warnings to be taken seriously. Although the park was established in 1934, lack of funding (the US was experiencing a depression at that time) meant that the Everglades National Park was not dedicated until 1947. By then, the park had been reduced to one third of the area contemplated in the original plan in order to accommodate private land holdings (Blake 1980).

Even at present, ecological restoration is almost entirely in the planning stage. Of course some restoration plans are quite a few years old. One example is the 'Re-Watering Plan' of the Florida Everglades, which addressed the problem of over-drainage and even advocated that some areas be permitted to revert to wetlands. A subsequent project involved installing a 100-mile-long perimeter levee to separate the Everglades from massive urban development. This plan eliminated 160 square miles of the Everglades (Lord 1993, Light \& Dineen 1994). The US Congress passed the Everglades National Park Expansion Act in 1984 in an attempt to provide a more natural distribution and timing of water delivery and in 1990 passed the Everglades Protection and Enhancement Act to enable purchase of 107600 acres of undeveloped land. The concept of sustainability was introduced in 1993 for the greater Everglades ecosystem. ${ }^{2}$ Finally, Congress approved the Comprehensive Everglades Restoration Plan in 2000 as part of the Water Resources Development Act.

This brief overview of a very complicated situation is intended to illustrate how quickly an ecological catastrophe can develop and how entrenched the new status quo can become. This catastrophe is the basis for some important points involving both eco-ethics and environmental politics:

1. Alterations of ecosystems, which 'look good on paper,' may quickly become persistent problems that pose both major ethical and political problems.

2. Legislative bodies (in this case the US Congress and the State of Florida legislature) may pass legislation that raises expectations but often results neither in major ecological restoration nor in a widely supported political decision.

3. As the complexity, duration of time, and acceptance of the damage increases, so do the difficulties in

${ }^{2}$ See http://www.evergladesplan.org/about/rest_plan_02.cfm restoring a self-regulating, naturalistic natural system. In some cases (e.g. wetlands), property rights became established, which were then difficult to expropriate.

4. The longer the damage continues, the fewer original species will be available for re-colonization.

5. Even ecosystem restoration professionals have little experience restoring large, damaged ecosystems to self-regulating systems.

6. The general public and political leaders must have a strong sense of eco-ethics as well as a high degree of environmental literacy and commitment to the ecosystem being restored.

7. The State of Florida or the US federal government, or both, have the legal authority (jurisdiction) to repair the ecological damage. Since they condoned the actions that caused the problem, they both have an ethical responsibility to correct it.

\section{Oceanic fisheries}

The oceanic ecosystem covers $70 \%$ of Earth's surface, but most of this system is not under the control of any nation, although the UN could have the power of persuasion, if not the power of military force, to ensure the ecosystem is not overexploited. World demand for seafood is well beyond the sustainable yield. The evidence for this demand is the shrinking fishery stocks, declining catches, and collapsing fisheries (Brown 2001).

The world fish harvest in 2000, the last year for which global data are available, was reported to be 94.8 million tons. Some three-fourths of oceanic fisheries are fished at or beyond their sustainable yields, and, in one third of these cases, stocks are declining. ${ }^{3}$ Larsen also reports that some scientists, when correcting for suspected over-reporting by China, the world's leading fishing nation, believe the global catch has declined by 360,000 tons each year since 1988 . Despite a tripling of fishing efforts, North Atlantic Ocean catches of a variety of fish popular with consumers have decreased by half. Larsen makes the important point that at least $\$ 2.5$ billion of US government money is used to subsidize fishing in the North Atlantic each year. ${ }^{4}$ These subsidies mask the fact that current fishing practices are both ecologically and economically unsustainable (Porter 2001). The vast extent of environmentally harmful government subsidies is well documented by Myers and Kent (1998).

${ }^{3}$ See Larsen J (2002) Fish catch leveling off. Eco-Economy Indicators, Earth Policy Institute, available online at http://www.earth-policy.org/Indicators/indicator3.htm ${ }^{4}$ See Footnote 3 
Larsen makes two extremely important points: (1) it takes twice as much fuel to catch a ton of fish today as it did 20 years ago and (2) the world's fishing fleet has the capacity to catch fish at more than twice the sustainable yield of the fisheries. ${ }^{5}$ Preventing an even greater ecological catastrophe in the oceanic fisheries than already exists is a major eco-ethical problem.

While oceanic fisheries are declining in many areas of the world, aquaculture of fish has grown about $10 \%$ annually and now accounts for approximately $27 \%$ of the world's edible fish supply. While agricultural technology has partially elevated the supply of fish, it has not solved the eco-ethical problem of preserving the oceanic ecosystems and their fisheries. Furthermore, some farmed oceanic fish, such as salmon, are fed with fish meal and oil obtained from oceanic sources. Thus, technology is still affecting oceanic fisheries (by harvesting small fish) and thus is still a major eco-ethical problem.

Fish farming has existed for thousands of years. In recent years, many hectares of rice paddies also have been used to raise fish. These fish are raised mostly in freshwater ponds, so they do not have an immediate effect upon oceanic ecosystems. However, fish hatcheries and, to a lesser extent, poly-culture of fish (with a grain crop) do produce wastes that will probably enter the hydrologic cycle and eventually reach the ocean.

The primary eco-ethical issues are quite clear: (1) a deliberate and world-wide reduction in harvesting oceanic fisheries until the harvest is clearly at a sustainable and ecologically sound level, (2) establishment of refugia (no-fishing zones) so that the stock can recover and provide a reservoir of species even if the management of larger areas is unsound, (3) contributions of individuals to this effort by greatly reduced consumption of oceanic fish and purchase of herbivorous aquaculture fish that are not fed on fish meal and oil from oceanic fisheries, (4) nations and individuals who go beyond sustainable harvesting of fisheries or do not respect refugia should suffer severe sanctions, as should all violators of sustainable practices, (5) a world science court should be established in the UN to ensure that the science used to implement the eco-ethical value judgments is robust, (6) in situations where the science is not robust and uncertainty exists about the outcome, precautions should be put in place to protect the oceanic fishery until robust information is available, and (7) in coping with any catastrophe, such as depleted oceanic fisheries, one should remember that sustainability is a multi-dimensional goal that will not be reached if component issues are examined in isolation from other eco-ethical issues related to sustainability.

${ }^{5}$ See Footnote 3

\section{Global climate change}

Robust evidence indicates that Earth's climate changed significantly even before humankind was present. Climate change from natural causes is difficult to manage, and it is possible to take the position that, even if humans could modify it to better suit their species, it might be prudent not to attempt doing so. However, persuasive evidence indicates that much of the recent climate change is markedly affected by anthropogenic activities of which, arguably, the most notable are those changes due to greenhouse gases (e.g. Brown 2001). The Goddard Institute for Space Studies of the US National Aeronautics and Space Administration (NASA) has shown that the 15 warmest years since record keeping began in 1867 have all occurred since 1980.

Although the thin envelope of atmosphere surrounding Earth is as important to the global commons as the oceanic fisheries, there are important differences: (1) the major problem for oceanic fisheries is removal of excessive amounts of stock, (2) the major problem for the atmosphere is the pollutants added from a variety of sources, (3) violators of the oceanic fishery are more likely to be seeking a profit and may have a sizable capital investment to recover, (4) violators of the atmospheric envelope are discharging pollutants into the atmospheric envelope to avoid spending money on waste treatment, (5) individuals contribute to the damage of both global systems, but, arguably, the aggregate of individual effects is greater for the atmospheric commons than for the oceanic commons, (6) by their actions, individuals can reduce the probability of a severe catastrophe in both arenas by reducing their own adverse effects, by letting corporations and governments know that they disapprove of their contributions to these adverse effects, and by boycotting products the corporations produce and the legislators who fail to protect these global systems.

While the increasing risk of a major atmospheric catastrophe is not fully appreciated by the general public, insurance companies are well aware of the risk. At the end of 2001, Munich Re (a company that helps spread risk among the various insurance companies) compiled a list of all the natural catastrophes on record with insured losses of US\$1 billion or more (as quoted in Brown 2002). By the end of 2001, the list of catastrophes with insured damages of US\$1 billion or more had reached 34. Brown (2002) also noted that Europe has experienced, in the last 15 years, an increased frequency of highly destructive winter storms. In Asia, rising sea levels could have a negative effect on rice production. The insurance industry is concerned about the effect of global warming on storm intensity. Even a seemingly insignificant increase of 0.5 to 1.0 degrees 
Celsius in the course of the next few decades could extend the hurricane season by several weeks, with a concomitant increase in the frequency and intensity of hurricanes. Melting of ice at the poles increases sea level rise (e.g. Brown 2001). Preparing for even a 1-m rise in sea level will require a very heavy investment in flood defenses worldwide. It is not clear either when such protection should be installed or who should pay for it. However, failure to provide protection will be very costly in human lives and property damage, but politicians are understandably reluctant to discuss the issue and most people, even the numerous residents of coastal areas, seem surprisingly unconcerned about the problem. Unless this situation is changed, coping will occur after the first major catastrophe - not before.

Death tolls due to heat waves have already been calculated. ${ }^{6}$ However, the death toll is not yet sufficiently high to result in widespread, lasting concern. However, since there has been a rising trend from 1866 to 2000 (Brown 2001), there is cause for concern.

Numerous books have been produced recently on global climate change, as well as much information in professional journals and internet sites of the UN, etc. (e.g. Olson 2004), and California even has an interfaith religious covenent to reduce global warming. ${ }^{7}$ The reason for concern is that trends indicate a worsening of the situation. The justification for cautious optimism is that there are remedial measures available with existing technology. This possibility, together with a changed energy policy in the US and other nations that consume much fossil fuel, should markedly reduce the risk of catastrophic climate change while simultaneously increasing the prospects for sustainable use of the planet.

As was the case for the previous examples, the primary eco-ethical issues are quite clear: (1) a deliberate, systematic, and orderly reduction in the unsustainable practices that have adverse effects upon global climate and especially activities that cause global warming; (2) appropriate remedial measures can be taken at all

${ }^{6}$ See India heat deaths exceed 1,000. 3 June 2003, available online at http://news.bbc.co.uk/1/hi/world/south_asia/ 2956490.stm

${ }^{7}$ See also Intergovernmental Panel on Climate Change (2001) Climate change: impacts, adaptation, and vulnerability (summary for policy makers), available online at www.ipcc.ch/pub/wg2SPMfinal.pdf; Environmental News Service, Spiritual, scientific leaders unite in global warming action plea. 21 May 2004, available online at www.keepmedia.com/ShowItemDetails.do?itemID $=472683 \&$ extID=10030\&oliID-226; California Interfaith Power \& Light, Congregational covenant, available online at www.interfaithpower.org/covenant.pdf; and Environmental News Service, Bank of America maps new climate change, forest policies. 18 May 2004, available online at www.forests.org/articles/reader.asp?linkid=31792 these levels of organization (individuals, regions, nations, and planet), with a strong commitment to ecoethics at all of these levels; (3) precautionary measures to prevent major global climate change are major ecoethical issues; 'death' of the sun and being struck by a sizable object from outer space would both be major global catastrophes, but, since humankind does not at present have proven technologies to cope with these events, they are not eco-ethical issues; (4) cost to society of the complex, multivariate problem of global warming; since the indirect costs of some goods and services are far greater than the price fixed by the marketplace, economics will not prevent ecological and human health catastrophes, although econ-ethics ${ }^{8}$ might do so; eco-ethics is more likely to value both ecosystem services and natural capital properly and place long-term sustainability above short-term profits and politics.

It is important to recognize that econ-ethics and ecoethics are not mutually exclusive. Econ-ethics is homocentric (e.g. Daly 2003) and eco-ethics is ecocentric. Both are essential to sustainable use of the planet. The two are interactive as the efforts to market natural capitalism demonstrate (e.g. Daily \& Ellison 2002).

\section{Overpopulation}

Sustainable use of the planet is based on the assumption that one species, Homo sapiens, can live in such a way that it can persist on the planet indefinitely. Despite this expectation, unsustainable practices are increasing at an alarming rate and are propelled by a human population growth of 74 million each year, unprecedented economic growth (driven by unprecedented consumption), and concomitant reduction in natural capital (natural systems). The increasing size of humankind's ecological footprint is already destroying habitats and species and threatening others. The inevitable consequence is shrinking per capita availability of resources for both humans and other species. The planet's ecological life support system is being severely damaged at a time when it is most needed. Grain production (which supplies food calories, both directly and indirectly), upon which humans depend, is not keeping pace with increased demand and is threatened by water shortages, loss of topsoil, desertification, and salinization of agricultural soils. All other species suffer greatly if they exceed the carrying capacity of their resource base. Technology and creativity can increase short-term carrying capacity for humans but cannot nullify natural law.

${ }^{8}$ Econ-ethics is defined by Professor Otto Kinne in Ethics in Environmental Science and Politics, ESEP 2002, p. 88-89 
Extending the period of economic growth has resulted in ecological deficits. These mounting ecological deficits are taking an increasingly severe economic toll. One does not need to be a Nobel Laureate to realize that the relationship between economics and ecology (both derived from oikos) cannot continue to deteriorate without severe consequences to both. Desertification is already causing major demographic shifts and is likely to produce even more environmental refugees unless it is halted.

If sea level rise continues, the demographic problems that will occur boggle the mind. Both dust storms (resulting from desertification) and sea level rise will affect adjacent countries. Dust storms originating in China have already had major social and economic effects upon South Korea. Cairns (2002) has discussed the effects of environmental refugees upon both neighboring and even distant countries. Since agriculture is heavily dependent upon water supplies (1 000 tons of water are required to produce 1 ton of grain; Doorenbos \& Kassam 1979), water and food shortages are the interrelated catastrophes most likely to get humankind's attention.

The eco-ethics question is how humankind will react when food/water shortages reach catastrophic levels. Iran, India and Yemen, Pakistan, and China already have water deficits, as do a number of other countries. World production of grain and other foodstuffs is threatened by a variety of factors. What is needed in both cases (food/water) is an ethical consensus on sustainable use of the planet, which I have termed sustainability ethics. ${ }^{9}$

\section{Epidemiological catastrophes}

Both globalization and increase in global population size increase the probability of epidemiological catastrophes. Globalization means an increase in transport of diseases to almost every area of the planet. Dense populations enhance local transmission of disease. Starvation, stress, etc., weaken resistance to disease.

Two types of epidemiological risks are relevant in an ecological context: (1) bioterrorism - either deliberate or inadvertent release of smallpox or other comparable 'weapons' of mass destruction and (2) rapid spread of a new virus, germ, etc. via the global transportation system, which could involve human carriers (e.g. AIDS), other biological transmitters (e.g. insects), transport on foodstuffs, and the like. Increasing human population

${ }^{9}$ See Cairns J Jr (2003) A preliminary declaration of sustainability ethics: making peace with the ultimate bioexecutioner. ESEP 2003:43-48; available online at www.esep.de/ articles/esep/2003/E30.pdf densities, especially those billions of humans with inadequate nutrition, health care, sanitation facilities, potable water supplies, shelter, and the like, exacerbate the problem. For example, infectious diseases are spread by recent immigrants (e.g. Dorey 2003, Howard 2003).

Recently, another country with a high immigration rate, Canada, is providing similar evidence. Fayerman reported nearly 400 active tuberculosis cases in British Columbia last year, which represented a $35 \%$ increase and was the first time in at least a decade that such a marked increase has been recorded. ${ }^{10}$ The British Columbia rate of 9.5 per 100000 population is nearly double Canada's national rate of 5.5 per 100 000. Public health officials attribute this increase to the high number of cases among immigrants, aboriginals, and those who live in Victoria City's downtown eastside.

There is no 'magic bullet' to solve these problems, but they will be dramatically reduced by the same measures that will improve the likelihood of sustainable use of the planet. It is important to recognize that: (1) these are basically ethical problems, although both science and technology will help reduce them once the ethical foundation has been laid and (2) nature has been dealing with overpopulation problems for millions of species for billions of years. Most species produce more individuals than their habitat can hold, and, from this large quantity of individuals, quality is selected. This system is hard on the individuals who lose, but it does protect both the species and the ecological system.

\section{ILLUSTRATIVE REGIONAL ECOLOGICAL CATASTROPHES}

The commingling of human artifacts (e.g. shopping malls, cities, parking lots, roads, etc.) and natural systems increases the potential for catastrophes in both systems. As the final draft of this manuscript was being produced, eight separate fires near San Diego, California, were raging out of control, and the two largest ones had merged into a single 40-mile red wall of fire. Experts had seen the fire coming for months (P. R. Ehrlich, pers. comm.) since climate, ecology, and inappropriate urbanization practices set the stage for one of the 'most perfect' firestorms in history. The fire has already caused 14 human deaths (and certainly far more wildlife deaths), destroyed nearly 1,000 homes, and, as reported by National Public Radio on 29 Octo-

\footnotetext{
${ }^{10}$ See Fayerman $\mathrm{P}$ (2002) Immigration fuels soaring TB rate: disease increases 35 percent in $\mathrm{B}$. C. to nearly twice the rate across Canada. Times Colonist (Victoria, British Columbia, November 21), available online at http://stoptb.org/material/ news/press/Times_Colonist_021121.htm
} 
ber 2003, devastated an area approximately the size of the US state of Rhode Island. In addition, uncounted thousands packed their cars with family treasures and fled. With all the dry timber available, the question was not 'if' a fire would occur, but 'when.' This situation is not unique - a similar but less devastating fire occurred near Canberra in Australia in January 2003.

The 100 miles of barrier sand islands off the coast of North Carolina, USA, provide a similar example in a different type of ecosystem. Hurricanes regularly relocate and reshape these barrier islands. In recent years, the narrow strip of land behind the beaches has been an almost unbroken stretch of huge holiday homes whose values are as much as US\$2 million each. However, Hurricane Isabel (September 2003) washed out most of the only road on the islands and tossed homes and motels around as if they were toys, and one island was cut into several islets.

Numerous cases worldwide show the folly of constructing houses and other human artifacts on the floodplains of rivers or other waterways. As is the norm for the previous examples, citizens who have suffered the consequences of commingling human artifacts and ecosystems not suited for that type of use usually appeal to the government to protect them from the penalties of their own injudicious decision. Human activities should be designed to be compatible with the ecosystems in which they occur since the practices just described are not sustainable.

\section{ECO-ETHICS: MANAGING THE GLOBAL COMMONS}

Economic globalization has converted the entire planet into a common ground. Access to it need not be physical, as originally envisioned by mathematician William Foster Lloyd in 1833. Economic access enables persons and organizations to exploit far distant resources and avoid responsibility for the consequences even better than when the commons are exploited by local inhabitants. The global commons is unmanaged in an ecological sense and even in an economic sense if economic development ignores humankind's responsibility to its descendants as well as those of other species. A widely accepted theorem of ecology is that it is impossible to do just one thing. Sustainable use of the planet requires that humankind do nothing that seriously depletes and/or damages both natural capital and ecosystem services. In an uncrowded world, a sustainability ethic would be less needed than it is now. Humankind now lives in a crowded world where leaving a habitable planet for future generations and those of other species is increasingly problematic.
Obviously an unmanaged commons is more likely to produce catastrophes than a skillfully managed commons. However, a managed commons requires a 'social contract' that produces responsibility for the consequences of inappropriate (i.e. unsustainable) practices. This contract, in turn, will require an 'ethics of the commons' and some forms of coercion, such as severe penalties for damage to the commons whether deliberate or accidental. Coercion is unpalatable but essential for those with less susceptible consciences. Prohibiting murder is an action that is widely accepted. Damaging the integrity of the planet's ecological life support system by damaging the commons is less easily grasped, even though it also results in loss of health and life for huge numbers of humans and other species. Every effort to protect the global commons will be vigorously opposed as infringements on individual 'rights' and 'freedom.' However, individual 'rights' and 'freedom' do not include the right to adversely affect posterity or the ecological life support system.

Nation-states will view protection of the global commons as an infringement of their sovereign rights. However, as the complexity of the stresses on the global commons increases, so does the risk of catastrophes and the need to take precautionary measures to prevent them. Nation-states themselves infringe on individual 'rights' and 'freedoms' in a variety of ways. Individuals cannot refuse to pay taxes even if they disapprove of the way their money is being spent. Individual freedom to drive at any speed, in any vehicle, and to park the vehicle wherever it is convenient (e.g. a parking space restricted to the handicapped) is severely limited. Individuals cannot defecate or urinate anywhere they choose. Humankind tends to accept these restrictions because they are now part of the status quo. New restrictions are resisted because those now living can perceive their personal loss and resist it, sometimes violently.

Sustainable use of the commons at present human population densities and level of affluence involves infringement on everyone's personal 'rights' and 'liberties.' Nature does not recognize individual 'rights' and 'liberties' if they involve exceeding the carrying capacity of the region or the planet. For humans, mere maintenance of life requires about 1600 kilocalories per day per individual. Any activities beyond maintenance (e.g. work, recreation) require additional calories. If humankind can figure out a way to increase resources without restricting the demand on them, an unmanaged global commons is at least theoretically possible and there is no need for infringement on individual freedoms. However, this possibility is remote and would not deserve attention if there were not a constant stream of assurances that an ever increasing supply of material goods for an increasing number of people would be available far into the future. 
The assumption that there is a 'free lunch' underlies humankind's economic system at present, while resource limitations underlie nature's economic system. This discontinuity occurs because the economic system of humankind depreciates anthropogenic artifacts (e.g. vehicles, industrial plants, automobiles) but not nature's capital upon which the human economic system depends. If economic development solely has resulted in unsustainable practices, perhaps it is high time to give econ-, eco-, sustainability ethics a chance to be the basis for sustainable use of the planet. The problem is that the latter produces long-term rewards, while the former produces short-term rewards, which are much more attractive to the average person who is not particularly concerned with ecological and sustainability ethics. Acknowledgement that technology alone will not solve all the problems it creates is long overdue. Humankind can keep improving the quality of life in a sustainable world. Sustainability is not stagnation! Co-evolving harmoniously with dynamic natural systems requires increased literacy about how they work and what paradigm shifts are necessary to maintain a harmonious relationship with them.

Some unpalatable realities, such as world poverty and consequent emigration and immigration, must be faced unflinchingly. At present the US, Canada, Australia, and a few other countries have a level of prosperity and social order unmatched in the rest of the world. Citizens of countries that cannot create comparable conditions are drawn to these countries as moths to a flame. The US, Canada, and Australia were mentioned because they were all recently colonized in evolutionary time, and their inhabitants are well aware that they are descendants of immigrants. Masters (2001) integrates ethics, ecology, and immigration into his discussion of this topic. It is repugnant to turn away new immigrants. However, countries with high immigration rates are also importing unsustainable practices (e.g. large families). Worse yet, they are being generous to immigrants with the resources that will be essential for a quality life for their descendants. If the same individuals had to decrease their personal resource use to accommodate immigrants, their enthusiasm for immigration would be markedly reduced. Even though corporations would still support immigration because of cheap labor, the citizens who would lose their employment would change their attitudes quickly. In fact, most citizens do not realize that there is no cornucopia from which resources will flow unceasingly in large quantities.

As Hardin (2001) describes the present situation, advocates of unrestrained immigration are proposing that the nation's citizens be figuratively thrown out of the 'lifeboat' to make room for strangers who are in the water because they could not manage their own 'lifeboat.' Hardin asserts that lifeboat ethics is merely a special application of the logic of the commons. However, the lifeboat analogy is much more understandable than an example involving the global commons. Yet, the paradigm is identical.

Turning the prosperous countries into a precarious human commons has already resulted in a high price in public health (e.g. Lutton 2003) ${ }^{11}$, crime $^{12}$, civil conflict (Cincotta et al. 2003), welfare ${ }^{13}$, and destruction of the existing culture ${ }^{14}$. Descendants in all parts of the planet will pay an even higher price if immigration continues at its present rate. Worse yet, the countries that have continually exported people to more affluent countries have not markedly benefited. One might view this remark as an elitist statement, so it clearly deserves elucidation. The Random House Dictionary, 2nd edition defines elitism as a practice of or belief in rule by an elite. Sociocultural selection has favored those cultures that have been most successful in acquiring resources. Living within the area or nation's carrying capacity is a basic need for humanity and the sine qua non of sustainable use of the planet. Confronting the challenges of overconsumption and poverty is also a major issue in achieving sustainability. Plato's carrying capacity (discussed by Durham 1994) was that the land must support a particular number of people in modest comfort. It is worth remembering that the available per capita ecological space on the planet has decreased, in the twentieth century, from between 5-6 hectares to 1.5 hectares (Wackernagel \& Rees 1996). The fossil energy use (in gigajoules/year) was 287 per person per year (in 1991) and 5 per person per year (in 1991) for India (Wackernagel \& Rees 1996, p. 85). One might well ask if greatly disproportionate use of Earth's resources is elitist. Some questions must be answered if immigrants are allowed to get aboard an ecological 'lifeboat.' Over half the world's population is living on US\$3 per day or less (the latest figures are always available from the UN). If as many as 1 billion individuals wish to immigrate to a more affluent country, such as the US, Canada, and Australia, many aspects of this immigration must be considered. Which of the one billion should be admitted? Should entrance be 'first come, first served'? Should entrance be based

\footnotetext{
${ }^{11}$ See also Camarota S (2000) Wrestling health care. Baltimore Sun, 22 August http://www.cis.org/articles/2000/sac8-2200.html

${ }^{12}$ See See Nunez P (2003) The deadly consequences of illegal alien smuggling. Testimony prepared for the US House of Representatives, Committee on the Judiciary, Subcommittee on Immigration, Border Security and Claims. 24 June http://www.cis.org/articles/2003/nuneztestimony062403.html ${ }^{13}$ See Krikorian M (1997) Will Americanization work in America? Freedom Review, fall issue. http://cis.org/articles/1997/ freedom_review.html

${ }^{14}$ See Footnote 13
} 
on need? How is any distinction handled and what is said to those who are excluded? A more detailed discussion of these issues can be found in Hardin (2001).

The dramatic novel of Raspail (1973) has often been cited to support the view that 'restricting the poor and miserable will not maintain or increase the overall well being of the planet and its biosphere.' However, the main point of the novel is the consequences of the citizens of the impoverished countries attempting to get the wealthy nations to share more of the world's resources. One factor is very clear - Earth is a finite planet with finite resources and neither is infinitely expandable. Reaching population stabilization is an extremely complex issue that is not likely to be resolved in a single publication. However, taking more resources from the 30+ million other species with which humankind shares the planet is neither ecologically nor ethically sound.

As noted elsewhere in this journal, I advocate positive action to stabilize world population and ensure a fair and equitable distribution of resources. ${ }^{15}$ These and other publications in ESEP recommend that wealthy nations assist less affluent countries in stabilization, as well as endorsing a fair and equitable distribution of resources. If the more affluent countries reduced the size of their ecological footprints and set an example by living sustainably, the world would have models to follow and more resources would be available to help other countries achieve sustainability.

\section{CONCLUSIONS}

Reducing catastrophes resulting from human activities is essential to sustainable use of the planet. Most societies are now sufficiently large, relative to their resource base, to preclude individuals from exercising complete control over their own destiny. Nation-states determine the fate of humankind. Thomas Jefferson's 1781 book Notes on Virginia warned of the dangers of importing peoples not literate in 'the freest principles of the English Constitution with others derived from natural right and natural reason.'

Catastrophes, resource wars, and political refugees will all probably increase (in rate, number, and severity) as humankind encounters resource limits. This statement then leads to coupling scientific knowledge with ecological and sustainability ethics as humankind addresses the central issue-population size and the natural resource base needed to support it cannot be

\footnotetext{
${ }^{15}$ See Cairns J Jr (2004) Allocating finite resources on a finite planet. ESEP 2004: 25-27, available online at http://www.esep.de/articles/esep/2004/E47.pdf; Cairns J Jr (2004) You and Earth's resources. ESEP 2004:9-11, available online at http://www.esep.de/articles/esep/2004/E45.pdf
}

separated. Migration of humans, including immigration, is generally viewed as an ethical issue, but there is a strong interconnection between human population size, both globally and locally, and the size and health of the natural resource base.

The fundamental issue of human survival (sustainable use of the planet) is how to develop a harmonious relationship between humankind and natural systems. Until this relationship develops, catastrophes of anthropogenic origin will occur and humankind must learn to cope with them. Better yet, by taking the precautions espoused by ecological and sustainability ethics, humankind can help avoid many of these catastrophes. The emotional attachment humankind has to its unsustainable practices is placing billions of people at risk.

Acknowledgements. I am indebted to K Cairns for typing the first draft of this manuscript, D Donald for editorial assistance, P Kullberg for calling my attention to useful publications, and to three reviewers for their helpful comments.

\section{LITERATURE CITED}

Agyeman J, Bullard RD, Evans B (2003) Just sustainabilities. MIT Press, Cambridge, MA

Blake NM (1980) Land into water - water into land: a history of water management in Florida. University Press of Florida, Tallahassee, FL

Brown LR (2001) Eco-economy. WW Norton, New York

Brown LR (2002) The earth policy reader. Earth Policy Institute, WW Norton, New York

Cairns J Jr (2002) Environmental refugees. TSC Jour 13(1):34-44

Cairns J Jr (2003) Carrying capacity, exponential growth, and resource wars: ethical dilemmas of human society. TSC Jour 14(1):56-63

Cincotta RP, Engleman R, Anastasion D (2003) The security demographic population and civil conflict after the Cold War. Population Action International, Washington, DC

Daily GC, Ellison K (2002) The new economy of nature. Island Press, Washington, DC

Daly HE (2003) Steady-state economics: concepts, questions, policies. TSC Jour 13(3):163-170

Doorenbos J, Kassam AH (1979) Yield Response to Water. United Nations Food and Agricultural Organization, Rome

Dorey J (2003) INS enforcement and immigrant borne diseases. TSC Jour 14(1):34

Dovell JE (1947) A history of the Everglades of Florida. PhD Dissertation, University of North Carolina, Chapel Hill, NC

Durham DF (1994) Carrying capacity philosophy. Focus $4(1): 5-7$

Hardin G (2001) Living on a lifeboat. TSC Jour 12(1):36-47

Hawken P, Lovins A, Lovins H (1999) Natural capitalism. Little, Brown \& Co, New York

Hendrickson DC (2002) Toward universal empire: the dangerous quest for absolute security. World Policy Jour Fall:1-10

Howard R (2003) SARS and tuberculosis. TSC Jour $14(1): 32-33$

Jefferson T (1781) Notes on Virginia. Virginia. As reproduced 
in Ford PL (ed) (1905) The works of Thomas Jefferson, Vol III (1780-1782), federal edn. GP Putnams Sons, New York Light S, Dineen J (1994) Water control in the Everglades: a historical perspective. In: Davis SM, Ogden JC (eds) Everglades: the ecosystem and its restoration. St. Lucie Press, Delray, FL, p 21-38

Lord LA (1993) Guide to Florida environmental issues and information. Florida Conservation Foundation, Winter Park, FL

Lutton W (2003) Immigration and public health. TSC Jour 14(1):12-20

Masters MW (2001) Ecology, ethics, and immigration. TSC Jour 12(1):5-12

McNeill JR (2000) Something new under the sun. WW Norton, London

McNeill JR, McNeill W (2003) The human web. WW Norton, New York

Menzel P (1994) Material world: a global family portrait. Sierra Club Books, San Francisco, CA

Myers N with Kent JV (1998) Perverse subsidies: tax \$s undercutting our economies and environment alike. International Institute for Sustainable Development, Winnipeg, Manitoba

Olson E (2004) Unnatural weather, natural disasters: a new UN focus. New York Times, 18 May, late edn-final:F2

Editorial responsibility: Guy R. Lanza, PhD (Editor), Amherst, MA, USA
Orr DW (2004) The last refuge. Island Press, Washington, DC

Porter G (2001) Fisheries subsidies and overfishing: towards a structured discussion. United Nations Environment Programme, Geneva, Switzerland

Raspail J (1973) The camp of the saints. English reprint by The Social Contract Press, Petosky, MI

Renner M (2002) The anatomy of resource wars. World Watch Paper 162, World Watch Institute, Washington, DC

Simpson CT (1920) In lower Florida wilds: a naturalist's observations on the life, physical geography, and geology of the more tropical part of the state. GP Putnam's Sons, New York

Small JK (1929) From Eden to Sahara — Florida's tragedy. Science Press Printing Company, Lancaster, PA

Smith B (1848) Report on Reconnaissance of the Everglades made to the Secretary of the Treasury, June 1848. Senate Rep. Com. No. 242, August 12, 1848. 30th Congress, 1st Session, Washington, DC, p 68

Swarns RL (2002) War-weary Angola meets new challenge: peace. New York Times, 28 April, late edn-final:A3

United Nations Development Programme (2001) Human development report 2001, Annex Tables 1, 4, 9. Oxford University Press, New York

Wackernagel M, Rees W (1996) Our ecological footprint: reducing human impact on Earth. New Society Publishers, Gabriola Island, BC, Canada

Submitted: April 15, 2004; Accepted: June 21, 2004

Proofs received from author(s): August 18, 2004

Published on the web: August 19, 2004 